\title{
Eficiência do uso da água pela cultura do amendoim sob diferentes lâminas de irrigação e formas de adubação
}

Mirandy dos Santos Dias ${ }^{1}$, Ligia Sampaio Reis ${ }^{2}$, Igor Ricardo Vasconcelos Lima², Abel Washington de Albuquerque $^{2}$, Rilbson Henrique Silva dos Santos ${ }^{2}$, Camila Alexandre Cavalcante de Almeida², Valdeí Marcelino Da Silva ${ }^{2}$

${ }^{1}$ Universidade Federal de Campina Grande - UFCG, PB. ${ }^{2}$ Universidade Federal de Alagoas - UFAL, Centro De Ciências Agrarias - CECA, AL. E-mail: mirandydias@gmail.com

\section{Resumo}

Objetivou-se, com este trabalho avaliar a eficiência do uso da água pela cultura do amendoim submetido a diferentes níveis de irrigação e formas de adubação. $O$ experimento foi conduzido em casa de vegetação no período de 20/03/2017 a 18/07/2017, no Campo Experimental do Centro de Ciências Agrárias, localizado no município de Rio Largo, AL. O delineamento experimental foi inteiramente ao acaso, no esquema fatorial $4 \times 2$, sendo quatro lâminas de irrigação $(50,75,100,125 \%$ da ETc) e duas formas de adubação (química e orgânica). Foram avaliadas as seguintes variáveis: número de folhas (NF), massa seca da raiz (MSR), massa seca da parte aérea (MSPA), número de grãos (NG), produção de grãos por planta (PGP), peso de grãos de em vagem (PGV) e a eficiência do uso de água (EUA). Constatou-se que a adubação orgânica, promoveu aumento no número de folhas e de grãos e que a máxima eficiência do uso da água pela cultura do amendoim, corresponde a $0,79 \mathrm{~g} \mathrm{~L}^{-1}$ de água consumida pela cultura, com a lâmina irrigação $62 \%$ da ETc, o que indica em elevada eficiência na transformação da água consumida em grãos.

Palavras-chave: Arachis hypogaea L.; manejo de água; produção.

\section{Efficiency of water use by peanut crop under different irrigation depths and forms of fertilization}

\begin{abstract}
The objective of this work was to evaluate the efficiency of water use by the peanut crop subjected to different irrigation levels and forms of fertilization. The experiment was carried out in a greenhouse in the period from 20/03/2017 to 18/07/2017, in the perimental field of the Agrarian Sciences Center, located in the municipality of Rio Largo, AL. The experimental design was completely randomized in the factorial scheme $4 \times 2$, four irrigation depths $(50,75,100,125 \%$ of ETc) and two forms of fertilization (chemical and organic). The following variables were evaluated: number of Leaves (NF), Root dry mass (MSR), shoot dry mass (MSPA), number of grains (NG), grain yield per plant (PGP), POD grain weight (PGV) and water use efficiency (US). It was found that the organic fertilization, promotes an increase in the number of leaves and grains and that the maximum efficiency of water use by the peanut crop, corresponds to $0.79 \mathrm{~g} \mathrm{~L}^{-1}$ of water consumed by the crop, with the irrigation depth $62 \%$ of ETc, which indicates in high efficiency in the transformation of the water consumed in grains.
\end{abstract}

Keywords: Arachis hypogaea L.; water management; production.

\section{Introdução}

O amendoim (Arachis hypogaea L.) é uma oleaginosa de grande importância econômica, cultivada em grande parte do mundo para atender a indústria química e alimentícia, na região semiárida ela é apontada como alternativa de rentabilidade para os pequenos produtores (FREITAS, 2011).

Sua relevância está relacionada também na diversidade de usos de seus grãos, que podem 
ser consumidos como alimento, tanto in natura como industrializado; é também utilizado pela indústria de conservas, biodiesel, óleos vegetais, e em padarias por ser um alimento rico em calorias, óleo, proteínas e vitaminas (SCARPIN et al., 2013; ARRUDA et al., 2015). Entretanto, para viabilizar a exploração dessa cultura em diferentes ecossistemas, faz-se necessário conhecer o comportamento dos parâmetros fisiológicos quando submetidos a diferentes tipos de estresse (GRACIANIO et al., 2011).

Assim como outras culturas de importância econômica, o amendoim também é sensível ao estresse hídrico, e sua resposta varia de acordo com a fase de desenvolvimento. Visto que, o déficit hídrico no período vegetativo resulta em alongamento do ciclo da cultura, e isto faz com que o produtor tenha maiores gastos com os tratos culturais. Se a falta de água ocorrer no florescimento, haverá queda de flores e murchamento de ginóforos, afetando diretamente a produção, enquanto que na frutificação a deficiência hídrica resulta em formação de grãos com menor peso específico, ou até mesmo o não preenchimento dos grãos, diminuindo a produção (NETO et al., 2012).

No Brasil, essa oleaginosa tem sido cultivada em condições de sequeiro, sujeitas a elevados riscos causados pelas variações de clima, incluindo a instabilidade de chuvas, ocasionando baixas produções. Na agricultura irrigada, deve-se atribuir uma atenção especial ao manejo da irrigação, a fim de garantir à disponibilidade de água durante todo o ciclo (SANTOS et al., 2012). Estimando de maneira precisa as necessidades hídricas da cultura, de forma que não ocorra déficit ou excesso, assim como o momento mais adequado para proceder à irrigação, visando, desta forma, maximizar a eficiência do uso da água (BILIBIO et al., 2010; AZEVEDO et al., 2014).

Visto que a água é essencial para o incremento da produção das culturas, por isso o seu uso deve ser feito de forma adequada para que se obtenha produções satisfatórias e altos rendimentos, isso exige o conhecimento sobre o crescimento das culturas e seu rendimento em diferentes condições (ARAGÃO et al., 2012).

O nível de produção da cultura do amendoim também está relacionado com a fertilidade do solo, em níveis de nutrientes que, facilmente, seria de um solo deficiente para outras culturas. No entanto a nutrição adequada do amendoim é primordial para a obtenção de alta produção e boa qualidade dos frutos, por mais que esta seja classificada como cultura pouco exigente em adubação (BOLONHEZI et al., 2005).

Para a recomendação correta da adubação, são necessárias informações relativas à nutrição de plantas, como a quantidade de nutrientes extraídos em cada estádio de desenvolvimento, e com essas informações é possível manejar a adubação de forma que os nutrientes sejam fornecidos na fase de maior requerimento, e assim aumentar a eficiência desta prática (LIMA, 2011). Diante do exposto, objetivou-se, com este trabalho avaliar a eficiência do uso da água pela cultura do amendoim (Arachis hypogaea L.), submetido a diferentes níveis de irrigação e formas de adubação.

\section{Material e Métodos}

O trabalho foi desenvolvido no período de 20/03/ 2017 a 18/07/2017, em casa de vegetação do Centro de Ciências Agrárias, pertencente a Universidade Federal de Alagoas, situado no município de Rio Largo - AL. Com coordenadas geográficas $9^{\circ} 27^{\prime} 55^{\prime \prime}$ de latitude Sul e $35^{\circ} 49^{\prime}$ $46^{\prime \prime}$ de longitude oeste, e altitude média de 127 $\mathrm{m}$.

O solo utilizado foi classificado como Latossolo Amarelo Coeso Argissólico com textura média/argilosa (EMBRAPA, 2006). Antes do plantio, foi realizada a análise química do solo na camada de 0 a $20 \mathrm{~cm}$, cujo resultado foi: $\mathrm{pH}=6,3$; $\mathrm{P}=41 \mathrm{mg} \mathrm{dm}{ }^{-3} ; \mathrm{K}^{2+}=101 \mathrm{mg} \mathrm{dm}{ }^{-3} ; \mathrm{Na}^{2+}=37 \mathrm{mg}$ $\mathrm{dm}^{-3} ; \mathrm{Ca}+\mathrm{Mg}=5,30 \mathrm{cmol} \mathrm{dm}^{-3} ; \mathrm{Al}^{3+}=0,02 \mathrm{cmol}$ $\mathrm{dm}^{-3} ; \mathrm{H}+\mathrm{Al}=2,80 \mathrm{cmol} \mathrm{dm}^{-3} ; \mathrm{SB}=5,72 \mathrm{cmol} \mathrm{dm}^{-3}$; CTC $=8,52 \% ; V=67,10 \%$.

A água utilizada para irrigação foi proveniente de um açude na área experimental, classificada como C1S1 (água com salinidade e concentração de sódio baixa), considerada uma água de boa qualidade para a irrigação (AYERS; WESTCOT, 1999).

O experimento foi conduzido em vasos de polietileno com capacidade para 15L, preenchidos com solo previamente seco ao ar. Foi utilizada a variedade de amendoim IAC Tatu Vermelho com as seguintes características morfológicas: Vagens do tipo Valência, apresentam ciclo de 90 a 110 dias, cor da película vermelha, teor de óleo de $48 \%, 3$ a 4 sementes por vagem, grãos de tamanhos pequenos e com características exigidas pelo mercado interno e pela indústria. 
0 delineamento adotado foi 0 inteiramente casualizado, em esquema fatorial 4 x 2, constituído de quatro lâminas de irrigação ( $\mathrm{T} 1=50 \%, \mathrm{~T} 2=75 \%$, T3 $=100 \%$ e T4 $=125 \%$ da ETc) e duas formas de adubações (A1 - química e A2 orgânica (esterco comercial), com 4 repetições.

As adubações foram realizadas de acordo com a análise de fertilidade do solo, seguindo a recomendação do Instituto Agronômico de Pernambuco para a cultura amendoim (IPA, 2008).

Para a adubação de plantio foi utilizado 20 kg $\mathrm{P}_{2} \mathrm{O}_{5}$ ha $^{-1}(0,83 \mathrm{~g}$ de superfosfato simples por vaso) e $10 \mathrm{~kg} \mathrm{~K}_{2} \mathrm{O} \mathrm{ha} \mathrm{ha}^{-1}(0,13 \mathrm{~g}$ de cloreto de potássio por vaso) em cobertura nos tratamentos de adubação química e $20 \mathrm{~m}^{3} \mathrm{ha}^{-1}$ de esterco comercial composto por estrume animal e pó de serra nos tratamentos de adubação orgânica (150 g por vaso).

Antes do plantio, os vasos foram preenchidos com 8,5 kg de solo e sua umidade foi elevada ao nível correspondente à capacidade de campo, para isso, foram saturados com água de baixa salinidade $\left(C E=0,17 \mathrm{dS} \mathrm{m}^{-1}\right)$, envolvidos individualmente com plástico, de forma a forçar a perda de água apenas por drenagem (GERVÁSIO et al., 2000). Logo após o final da drenagem, os vasos foram pesados para determinar a capacidade de campo, assim a partir dessa foi determinado às lâminas de cada tratamento, onde foi tomada como base a evapotranspiração da cultura (ETc), que no balanço hídrico é a lâmina de irrigação menos a água que drenou.

As irrigações foram realizadas a cada dois dias (turno de rega de 2 dias), onde eram pesados dois vasos de cada tratamento, obtendo-se a média desses valores e retornando-se, então, ao peso-controle para os devidos tratamentos.

A colheita foi realizada aos 105 dias após semeadura (DAS) e foram avaliadas as seguintes variáveis: número de folhas (NF), massa seca da raiz (MSR), massa seca da parte aérea (MSPA), número de grãos (NG), produção de grãos por planta (PGP), peso de grãos de amendoim em vagem (PGV) e a eficiência do uso de água (EUA).

Para obtenção da massa fresca da parte aérea as plantas foram pesadas em balança digital logo após a colheita. Após a pesagem foram colocadas em sacos de papel, identificadas e levadas para secar em estufa com circulação forçada de ar, a $65{ }^{\circ} \mathrm{C}$ constante, durante 72 horas. Após este período, as amostras foram pesadas para a determinação da massa seca. Para obtenção da área foliar (AF), foi utilizado o integrador de área foliar modelo LI 3100 da Licor.

A eficiência do uso da água $\left(\mathrm{g} \mathrm{L}^{-1}\right)$ para a produtividade de grãos foi obtida pela relação entre a produção de grãos e a lâmina de água aplicada durante o ciclo da cultura (Equação 1).

$$
\begin{aligned}
& E U A=P / I \\
& \text { (Equação 1) }
\end{aligned}
$$

Em que:

EUA - Eficiência do uso da água, $\mathrm{g} \mathrm{L}^{-1}$;

$P$ - Produção de grãos, g;

I - Lâmina de água aplicada pela irrigação, L

Os dados coletados foram submetidos à análise de variância, com o auxílio do programa estatístico ASSISTAT 7.7 (SILVA; AZEVEDO, 2016).

\section{Resultados e Discussão}

$\mathrm{Na}$ análise de variância apresentada na Tabela 1, observa-se efeito significativo das lâminas de irrigação (LI) $(p>0,01)$ para todos os componentes de produção da cultura do amendoim enquanto para adubação $(A)$, houve efeito significativo $(p>0,05)$ apenas para as variáveis número de folhas e número de grãos.

Quanto a interação Lâminas de Irrigação $\times$ Adubação, não houve diferença pelo teste $F$ para as variáveis analisadas, indicando que nestas variáveis a adubação não interferiu no estresse hídrico da cultura. 
Tabela1. Resumo das análises de variância e coeficientes de variação para os componentes de produção: número de folhas (NF), massa seca da raiz (MSR) (g) e massa seca da parte aérea (MSPA) (g), número de grãos (NG), produção de grãos por planta (PGP) (g), peso dos grãos em vagem (PGV) (g) e a eficiência do uso da água (EUA) (g $\left.\mathrm{L}^{-1}\right)$.

\begin{tabular}{lcccccccc}
\hline \multirow{2}{*}{ CAUSA DE VARIAÇÃO } & \multirow{2}{*}{$\mathrm{GL}$} & \multicolumn{7}{c}{ QM } \\
\cline { 2 - 8 } & & $\mathrm{NF}$ & $\mathrm{MSR}$ & $\mathrm{MSPA}$ & $\mathrm{NG}$ & $\mathrm{PGP}$ & PGV & EUA \\
\hline L. Irrigação (LI) & 3 & $49733,8^{* *}$ & $120,9^{* *}$ & $170,9^{* *}$ & $1342,46^{* *}$ & $505,61^{* *}$ & $1789,99^{* *}$ & $0,28^{* *}$ \\
Adubação (A) & 1 & $24420,5 \mathrm{~ns} *$ & $43,5 \mathrm{~ns}$ & $307,2 \mathrm{~ns}$ & $2278,13^{*}$ & $406,48 \mathrm{~ns}$ & $885,68 \mathrm{~ns}$ & $0,002 \mathrm{~ns}$ \\
Interação (LI x A) & 3 & $3116,5 \mathrm{~ns}$ & $13,4 \mathrm{~ns}$ & $156,2 \mathrm{~ns}$ & $747,46 \mathrm{~ns}$ & $178,66 \mathrm{~ns}$ & $422,26 \mathrm{~ns}$ & $0,05 \mathrm{~ns}$ \\
Reg. Linear & 1 & $123432,10^{* *}$ & $336,22^{* *}$ & $4427,13^{* *}$ & $3515,62^{* *}$ & $1075,10^{* *}$ & $4418,92^{* *}$ & $0,67^{* *}$ \\
Reg. Quadrática & 1 & $23112,50^{*}$ & $26,20 \mathrm{~ns}$ & $491,01^{*}$ & $496,12 \mathrm{~ns}$ & $421,44^{*}$ & $950,15 \mathrm{~ns}$ & $0,13^{*}$ \\
Resíduo & 24 & 6152,8 & 12,9 & 89,3 & 336,25 & 103,49 & 282,71 & 0,03 \\
\hline C.V.\% & - & 21,8 & 31,3 & 25,6 & 27,55 & 30,18 & 28,88 & 24,91 \\
\hline
\end{tabular}

ns: Não significativo a $5 \%$ de probabilidade pelo teste $\mathrm{F} ;{ }^{* *}$ : Significativo a $1 \%$ de probabilidade pelo teste $\mathrm{F}$, ${ }^{*}$ : Significativo a $5 \%$ de probabilidade pelo teste $\mathrm{F}$.

$\mathrm{Na}$ Tabela 2, encontra-se os valores médios das variáveis analisadas em relação aos diferentes tratamentos. Observa-se que não houve diferença estatística para as variáveis massa seca da raiz, massa seca da parte aérea, produção de grãos por planta, peso de grãos em vagens e a eficiência no uso da água.

No entanto para as variáveis número de folhas e número de grãos, houve diferença quanto ao tipo de adubação, apresentando médias de 387,7 folhas e 75 grãos para a adubação orgânica, enquanto para a adubação química 322,5 folhas e 58,12 grãos por planta.
Essa diferença pode ser explicada pelo fato que a adubação orgânica além de fornecer nutrientes, melhora as características físicas, químicas e biológicas do solo, aumentando a ação dos microrganismos, resultando no melhor aproveitamento dos nutrientes do próprio solo, de forma gradativa e contínua, resultando em maior equilíbrio nutricional para a cultura (GALBIATTI et al., 2011). Alves et al. (2016), trabalhando com a cultura do algodão também constataram que com a utilização da adubação orgânica, houve aumento no número de folhas.

Tabela 2. Quadro de médias dos componentes de produção e eficiência do uso da água pela da cultura do amendoim.

\begin{tabular}{lccccccc}
\hline ADUBAÇÕES & NF & MSR & MSPA & NG & PGP & PGV & EUA \\
\hline ORGÂNICA & $387,7 \mathrm{a}$ & $12,64 \mathrm{a}$ & $39,99 \mathrm{a}$ & $75,0 \mathrm{a}$ & $37,26 \mathrm{a}$ & $63,47 \mathrm{a}$ & $0,65 \mathrm{a}$ \\
QUÍMICA & $332,5 \mathrm{~b}$ & $10,31 \mathrm{a}$ & $33,79 \mathrm{a}$ & $58,12 \mathrm{~b}$ & $30,13 \mathrm{a}$ & $52,95 \mathrm{a}$ & $0,66 \mathrm{a}$ \\
\hline
\end{tabular}

Médias seguidas pela mesma letra nas colunas não diferem entre si estatisticamente pelo teste de Tukey em nível de $5 \%$ de probabilidade.

Pela análise de regressão, verifica-se na Figura 1 que o número de folhas, em função das lâminas de irrigação, se ajustou em um modelo polinomial quadrático, com $\mathrm{R}^{2}$ de 0,98 . Observase que o déficit hídrico ocasionou em redução no número de folhas, visto que a reposição de 50 e $75 \%$ da ETc resultou em 254 e 374 folhas, respectivamente. De acordo com Taiz et al. (2017), os processos fisiológicos são afetados pelo estresse hídrico haja vista que em condição de menor disponibilidade de água as plantas mantêm suas células das zonas de crescimento em condições de flacidez reduzindo o coeficiente da divisão celular e a expansão das células prejudicando o crescimento das plantas.

A redução do número de folhas em plantas sob estresse hídrico pode ser considerada com uma estratégia de sobrevivência, a fim de evitar perdas de água por transpiração, provocando alterações morfológicas e anatômicas nas plantas a ponto de desbalancear a absorção de água e a taxa transpiratória. Dentre as mudanças morfológicas, as reduções do número e tamanho das folhas são as mais expressivas (DIAZ LÓPEZ et al., 2012). Isto se deve ao fato de que o déficit hídrico reduz a 
multiplicação e divisão celular no interior do tecido vegetal, o que resulta em menor crescimento da parte aérea das plantas, que como mecanismo de defesa ao início da restrição hídrica reduzem a expansão foliar e a eficiência fotossintética (TAIZ et al., 2017).
Além disso, percebe-se que a lâmina máxima estimada de irrigação, na qual obtêm-se maior média no número de folhas para a cultura do amendoim é de $113,37 \%$ da ETc. Sendo assim, aplicando esta lâmina a cultura apresenta uma média de 422 folhas por planta.

Figura 1. Número de folhas da cultura do amendoim, sob diferentes lâminas de irrigação.

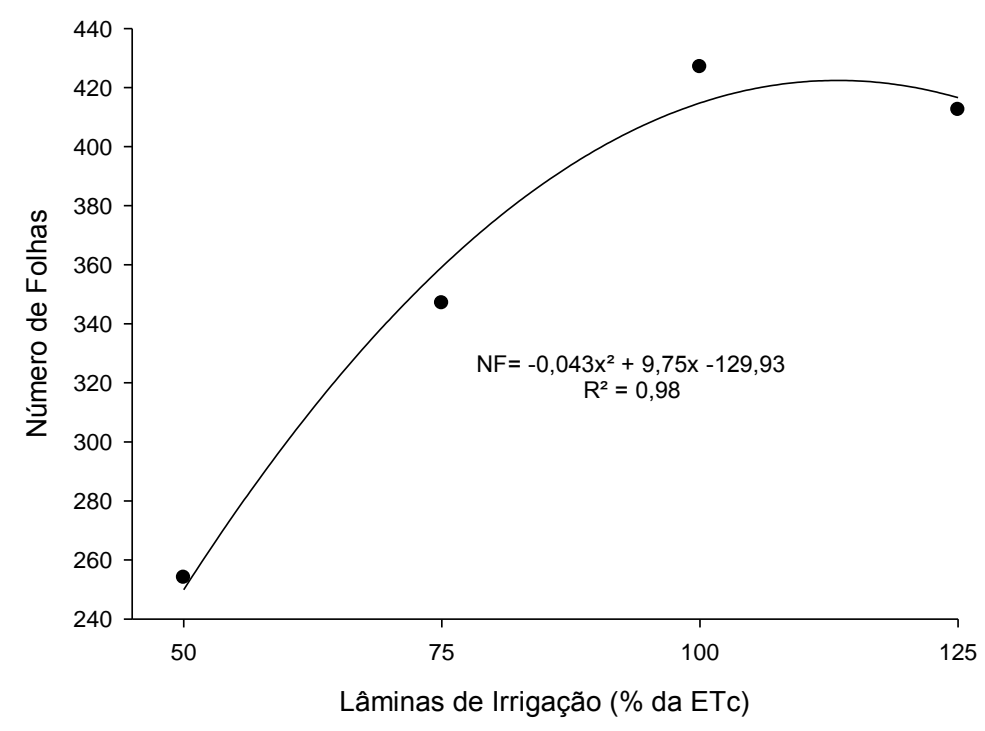

A massa da raiz (Figura 2) apresentou resposta linear crescente em função das lâminas de irrigação, ajustando-se ao modelo quadrático, $\mathrm{R}^{2}$ de 0,93 , onde os valores médios aumentaram de $6,26 \mathrm{~g}$ para $14,89 \mathrm{~g}$, com superioridade de aproximadamente $137 \%$ entre 50 e $125 \%$ da ETc. Este efeito linear para a massa seca da raiz pode ser atribuído ao acréscimo na lâmina de irrigação, visto que o fornecimento de lâminas excessivas pode ocasionar uma maior produção de fotoassimilados, consequentemente em um maior acúmulo de biomassa das raízes.

Figura 2. Massa seca da raiz de plantas de amendoim, sob diferentes lâminas de irrigação.

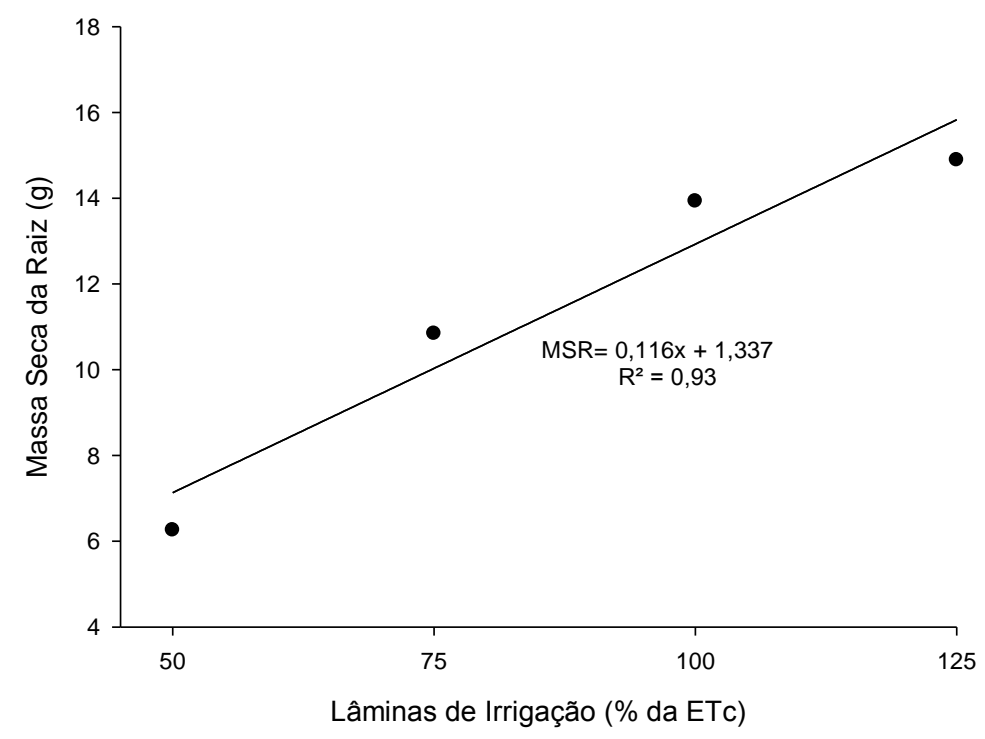


Verifica-se pela Figura 3, que o acréscimo das lâminas de irrigação refletiu em efeito significativo na massa seca da parte aérea do amendoim. $\mathrm{O}$ modelo que melhor se ajustou ao conjunto de dados médios de massa seca da parte aérea foi 0 polinomial quadrático, apresentando um $R^{2}$ de 0,95 . Essas informações implicam que $95 \%$ das variações ocorridas no parâmetro massa seca da parte aérea podem estar relacionadas com as diferentes lâminas de irrigação. A lâmina máxima estimada desta variável para o amendoim foi $120,39 \%$ da ETc, com isso, aplicando esta lâmina a cultura apresenta uma média no acúmulo de massa seca de 48,29 gramas.

Figura 3. Massa seca da parte aérea de amendoim em função de diferentes lâminas de irrigação.

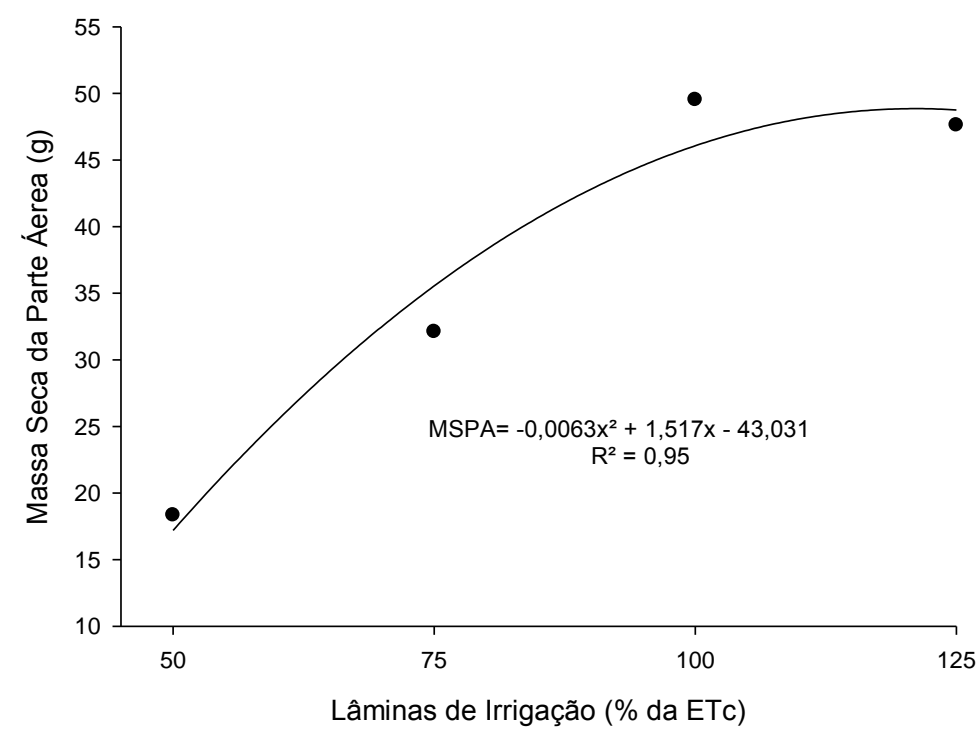

Nota-se que as lâminas 50 e $75 \%$ da ETc, apresentaram menor acúmulo de massa seca (18, 34 e 32,10 gramas, respectivamente) quando comparado à lâmina com as lâminas 100 e $125 \%$ da $\operatorname{ETc}(49,52$ e 47, 61 gramas, respetivamente). De acordo com Duarte et al. (2013), o estresse hídrico provoca alterações nas propriedades das membranas, aumento da respiração, inibição da fotossíntese, menor produção de matéria seca, senescência prematura e redução na produção e seus componentes.

Porém, percebe-se que que lâminas superiores a máxima determinada, podem acarretar no decréscimo no acúmulo de massa seca. Esses dados reforçam a teoria que a água quando aplicada em quantidades superiores a exigida pela cultura, a mesma poderá não responder de forma positiva, pois à presença da maior umidade na superfície pode ter acarretado em um menor desenvolvimento da mesma.

De acordo com Oliveira et al. (2005), o teor de massa seca da parte aérea pode ser considerado um indicador de produtividade, pois com o estresse hídrico, a planta fecha os estômatos para manter o potencial de água na folha, assim reduz a assimilação de $\mathrm{CO}_{2} \mathrm{e}$, por conseguinte os fotoassimilados, e dessa forma os teores de massa seca da planta, bem como o crescimento e a produtividade podem ser reduzidos.

Ao se analisar o efeito da irrigação sobre o número de grãos, constatou-se que o modelo que melhor se ajustou aos dados foi o linear crescente, com $R^{2}=0,87$ (Figura 4).

Com relação a este componente de produção, quando se aplicou as lâminas $75 \%$, $100 \%$ e $125 \%$ da ETC, houve um aumento no número de grãos $(66,75,74,25$ e 77 grãos por planta, respectivamente), quando comparado com a menor lâmina $50 \%$ da ETc $(48,25$ grãos por planta). Visto que o suprimento adequado de água e nutrientes são fatores que afetam diretamente $o$ desenvolvimento e a produtividade das culturas agrícolas (ANJUM et al., 2011).

O baixo número de grãos, atribuído a lamina de $50 \%$ da ETc está associada a ocorrência do déficit hídrico, que provoca o fechamento dos estômatos, diminuindo a assimilação de $\mathrm{CO} 2$, fotoassimilados e consequentemente, as 
atividades fisiológicas das plantas, ocasionando redução no crescimento e afetando a formação e desenvolvimento de grãos. De acordo com Boote et al. (1976), o estresse hídrico nas fases de crescimento e desenvolvimento dos ginóforos e das vagens, acarreta decréscimo na produção, pela redução do número de vagens, seu peso e o número de sementes podem ser prejudicados. Visto que a produtividade do amendoim está associada ao número total de ginóforos e a altura do ginóforo (LUZ et al., 2010).

Figura 4. Número de grãos de amendoim em função de diferentes lâminas de irrigação.

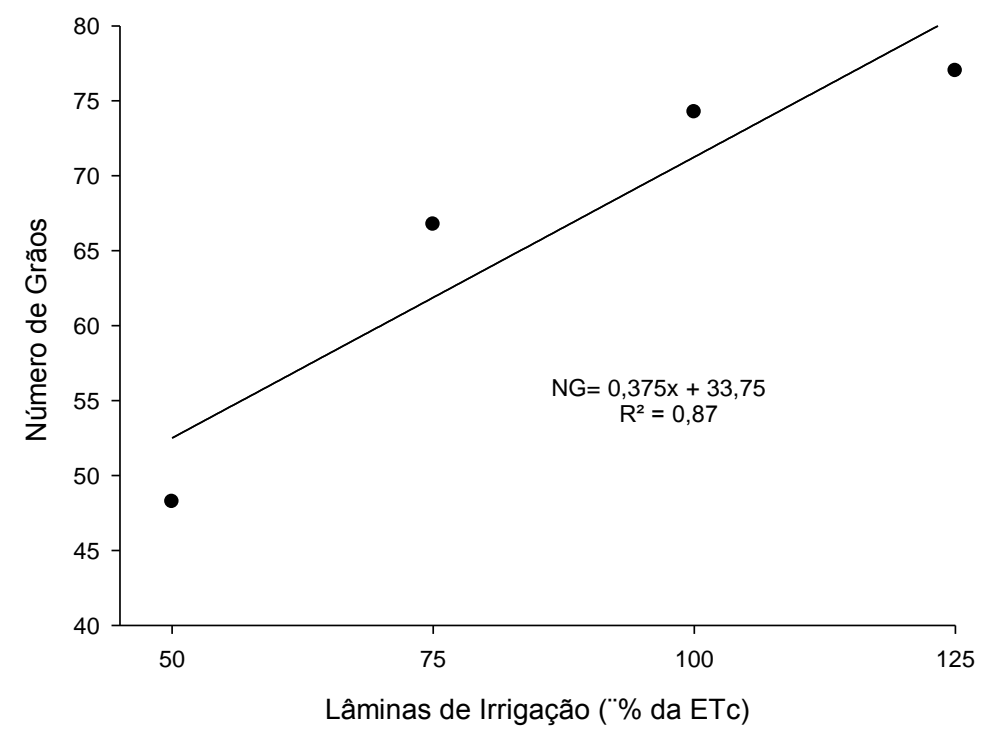

Observa-se que o déficit hídrico ocasionou em grandes perdas produtivas no amendoim, onde o mesmo necessita de condições favoráveis para atingir seu potencial ótimo de produtividade, como quantidade de água necessária para seu desenvolvimento e produção, com uma nutrição adequada.

Comparando a produção de grãos por planta, obtido pela lâmina de $100 \%$ de reposição (Figura 5), foi observado uma queda no rendimento pelo tratamento de $50 \%$ de reposição (aproximadamente 22 gramas por planta).

Verifica-se na mesma, que a lâmina máxima de irrigação estimada para a produção de grãos foi de $105,51 \%$ da ETc, valor este que irá proporcionar para a variável produção de grãos 40,18 gramas por planta. Neste contexto, observa-se que lâminas superiores a máxima recomendada pode acarretar em um decréscimo na produção dos grãos (PG) em gramas. De acordo com Machado et al. (2009), o manejo correto da disponibilidade hídrica reduz significativamente as perdas e proporciona condições favoráveis para o desenvolvimento vegetativo das plantas. 
Figura 5. Produção de grãos sob diferentes lâminas de irrigação.

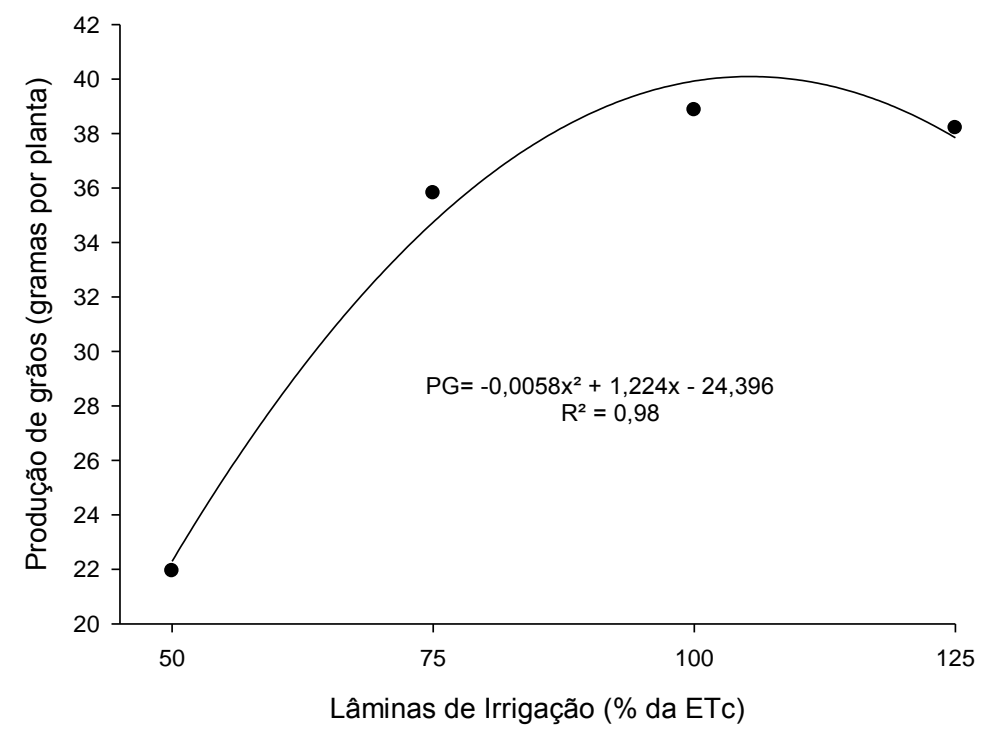

Para a variável peso de grãos em vagens (Figura 6), observa-se resposta linear crescente, em função das lâminas de irrigação, onde os valores aumentaram de 36,92 (50\% da ETc) para $68,69 \mathrm{~g}$ (100\% da ETc), equivalente a $86,05 \%$ de aumento no peso dos grãos.

O déficit hídrico ocasionou perdas no peso dos grãos em vagens de aproximadamente 47\%, com relação à aplicação da lâmina para manter o solo com $100 \%$ Etc. Essa redução pode ser explicada pelo fato de que a deficiência hídrica provoca o fechamento dos estômatos, diminuindo a assimilação de $\mathrm{CO}_{2}$ e, consequentemente, as atividades fisiológicas das plantas, em especial a divisão e o crescimento das células, influenciando diretamente na produção, conforme se observou, também Arruda et al. (2015), que a deficiência hídrica, provoca diminuição na taxa fotossintética, ocasionando redução no crescimento da planta e afetando a formação e desenvolvimento de grãos, os quais influenciam diretamente na produção.

Ainda com relação à produtividade, Oliveira et al. (2012) explicam que as plantas de amendoim, quando sujeitas ao déficit hídrico nas fases de crescimento e desenvolvimento das vagens, a produção de vagens, seu peso e o número de sementes podem ser prejudicados. 
Figura 6. Peso de grãos em vagens da cultura do amendoim sob diferentes lâminas de irrigação.

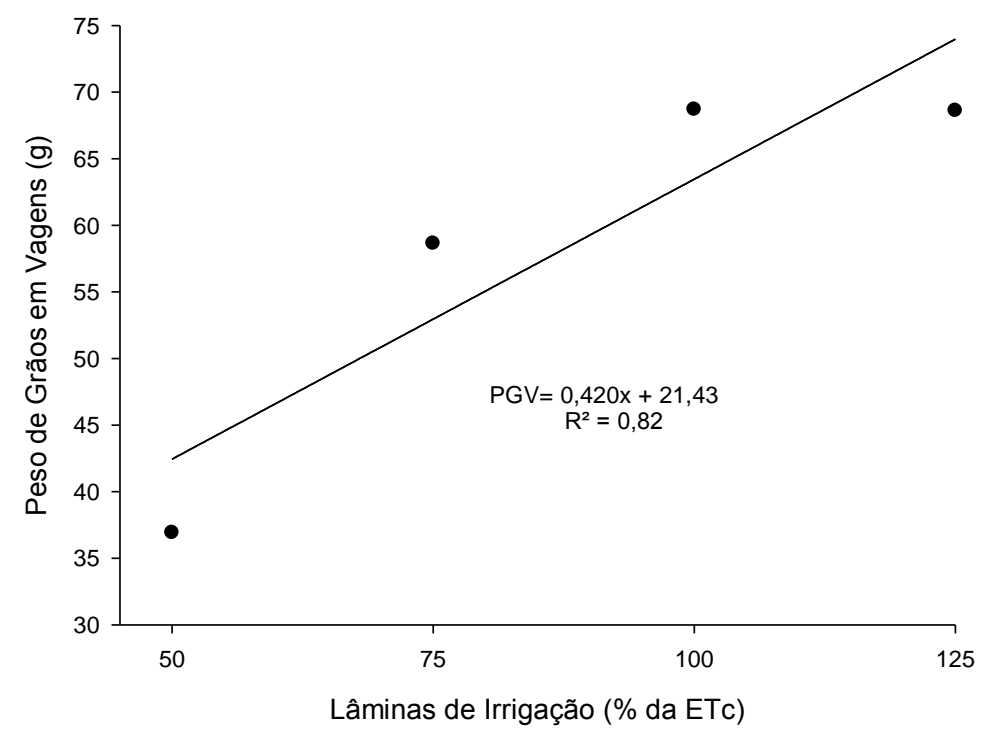

Para a eficiência do uso da água sob o efeito das diferentes lâminas de irrigação, notase que o modelo quadrático foi o que melhor se ajustou ao conjunto de dados médios deste parâmetro, com um ajuste de 95\% (Figura 7). A lâmina máxima estimada de irrigação, na qual se obtêm maior eficiência do uso de água para a cultura do amendoim foi de $62 \%$ da ETc, valor este que irá proporcionar uma eficiência no uso da água de $0,79 \mathrm{~g} \mathrm{~L}^{-1}$, sendo assim, com aplicação de lâminas superiores a máxima determinada (62\% da ETc), as plantas diminuem a eficiência no uso da água. Estes resultados corroboram com Sousa et al. (2008) estudando a eficiências do uso da água pela cultura da mamona sob diferentes laminas de irrigação, também verificaram que a eficiência do uso da água decai com o incremento na lâmina aplicada.

Figura 7. Eficiência do uso da água pela cultura do amendoim sob diferentes lâminas de irrigação.

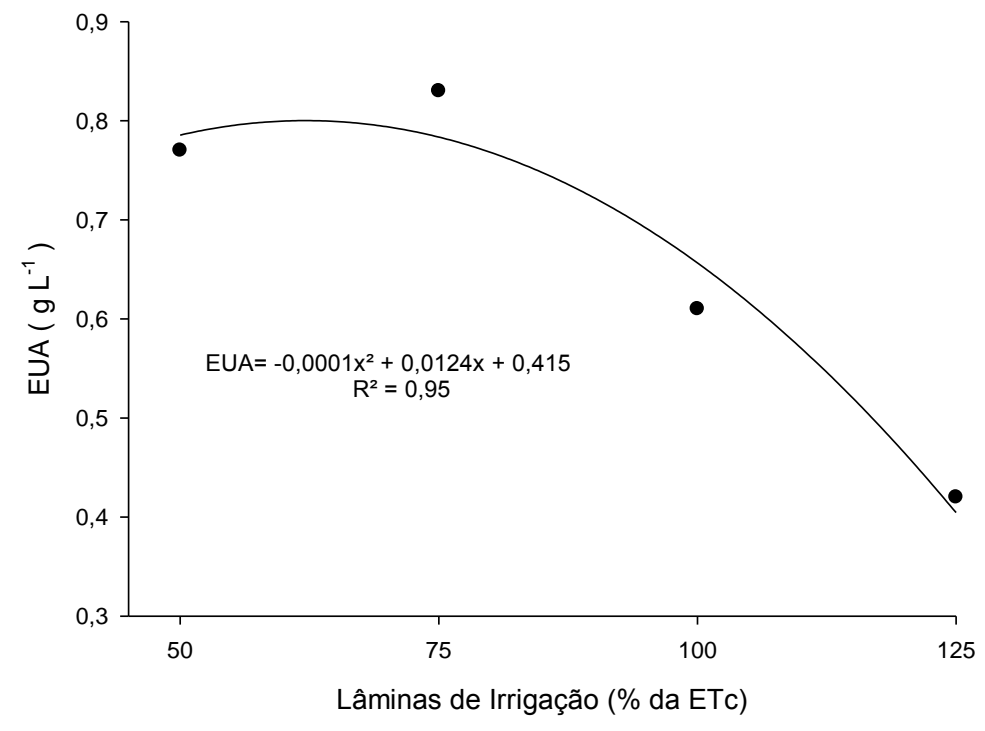


As lâminas de $50 \%$ da ETc, proporcionou uma boa eficiência $\left(0,77 \mathrm{~g} \mathrm{~L}^{-1}\right)$ no uso da água na cultura do amendoim. De acordo Taiz et al. (2017), quando o estresse hídrico, a eficiência do uso da água pode aumentar, devido a diminuição na condutância estomática, a qual afeta com maior intensidade a taxa fotossintética do que a taxa transpiratória da folha e quando torna severo, a desidratação de células do mesofilo inibe a fotossíntese, com isso o metabolismo do mesofilo é prejudicado e a eficiência no uso da água.

Porém mediante a escolha da melhor lâmina a ser aplicada não se deve levar em consideração apenas a lâmina que proporciona maior produção e melhor eficiência no uso da água, torna-se necessário analisar outros fatores como: disponibilidade energética, hídrica e também alguns indicadores de produtividade da água, que expressam benefícios derivados do consumo de água pelas culturas e podem ser usados para avaliar o impacto das estratégias de exploração agrícola em condições de escassez de agua. Eles fornecem uma visão adequada de onde a água poderia ser economizada (FRIZZONE et al., 2014).

\section{Conclusões}

A adubação orgânica promove aumento no número de folhas e de grãos em plantas de amendoim;

Na presença de estresse hídrico há perdas em todos os componentes de produção da cultura do amendoim;

A lâmina de irrigação 105,51\% da ETc proporciona a maior produção de grãos;

A máxima eficiência do uso da água, corresponde a lâmina de irrigação de $62 \%$ da ETc, o que indica em elevada eficiência na transformação da água consumida em grãos.

\section{Referências}

ALVES, L.; VERAS, M. L. M.; MELO FILHO, J. S.; SOUSA, N. A.; FERREIRA, R. S.; FIGUEIREDO, L. F.; ALVES, E. C.; BELARMINO, K. S.; SOUZA, M. A.; MESQUITA, E. F. Growth aspects and production of cotton under salt stress as a function of organic fertilizer. African Journal of Agricultural Research, n.11, p.4480-4487, 2016. https://doi.org/10.5897/AJAR2016.11573

ANJUM, S. A.; YU XIE, X.; WANG, L. C.; SALEEM, M. F.; MAN, C.; LEI, W. Morphological, physiological and biochemical responses of plants to drought stress. African Journal of Agricultural Research, Victoria Island, v. 6, n. 9, p. 2026-2032, 2011. Doi: 10.5897/AJAR10.027

ARAGÃO, V. F.; FERNANDES, P. D.; GOMES FILHO, R. R.; CARVALHO, C. M.; FEITOSA, H.O.; FEITOSA, E. O. Produção e eficiência no uso de água do pimentão submetido a diferentes lâminas de irrigação e níveis de nitrogênio. Revista Brasileira de Agricultura Irrigada v. 6, n. 3, p. 207-216, 2012. https://doi.org/10.7127/rbai.v6n300086

ARRUDA, M. I.; MODA-CIRINO, V.; BURATTO, S. J.; FERREIRA, M. J. Crescimento e produtividade de cultivares e linhagens de amendoim submetidas a déficit hídrico. Pesquisa Agropecuária Tropical, Goiânia, v. 45, n. 2, p. 146-154. 2015.

AYERS, R. S.; WESTCOT, D. W. A qualidade da água na agricultura. Campina Grande: UFPB, 1999.

AZEVEDO, B. M; SOUSA G. S; PINTO PAIVA, T. F.; MESQUITA, J. B. R.; VIANA, T. V. A. Manejo da irrigação na cultura do amendoim. Magistra, Cruz das Almas, v. 26, n. 1, p. 11-18, 2014.

BILIBIO, C.; CARVALHO, J. A.; MARTINS, M. A.; REZENDE, F. C.; FREITAS, E. A.; GOMES, L. A. A. Desenvolvimento vegetativo e produtivo da berinjela submetida a diferentes tensões de água no solo. Revista Brasileira de Engenharia Agrícola e Ambiental, Campina Grande, v. 14, p. 730-735, 2010. https://doi.org/10.1590/S1415$\underline{43662010000700007}$

BOLONHEZI, D.; PEREIRA, J. C. V. N. A.; GODOY, I. J.; GENTILIN JR., O; FREITAS, S. S. Manejo cultural do amendoim. In: $O$ agronegócio do amendoim no Brasil. Campina grande: Embrapa-CNPA, 2005. $451 \mathrm{p}$.

BOOTE, K. J.; VARNELL, R. J.; DUNCAN, W. G. Relationships of size, osmotic concentration, and sugar concentration of peanut pods to soil water. Proceedings Soil and Crop Science Society of Florida, v.35, p.47- 50, 1976.

DIAZ-LÓPEZ, L. D.; GIMENO, V.; LIDÓN, V.; SIMÓN, I.; MARTÍNEZ, V.; SÁNCHEZ, F. G. The tolerance of Jatropha curcas seedlings to $\mathrm{NaCl}$ : An ecophysiological analysis. Plant Physiology and Biochemistry, Paris, v. 54, n. 2, p. 34-42, 2012. https://doi.org/10.1016/i.plaphy.2012.02.005 
DUARTE, E. A. A., MELO FILHO, P. A.; SANTOS, R. C. Características agronômicas e índice de colheita de diferentes genótipos de amendoim submetidos a estresse hídrico. Revista Brasileira de Engenharia Agrícola e Ambiental, Campina Grande, v. 17, n. 8, p. 843-847, 2013. https://doi.org/10.1590/S1415-

\section{7}

EMBRAPA. Sistema brasileiro de classificação de solos. Rio de Janeiro: Embrapa Solos, 2006.

FREITAS, G. A. de. Produção e área colhida de amendoim no Nordeste. 3. ed. Banco do Nordeste, Fortaleza, 2011.

FRIZZONE, J. A; LIMA, S. C. R. V.; COSTA, R. N. T. Irrigação: da conservação de agua e solo à sustentabilidade com vistas à autogestão. Fortaleza: INOVAGRI, 2014. 129p.

GALBIATTI, J. A.; SILVA, F. G.; FRANCO, C. F.; CARAMELO, A. D. Desenvolvimento do feijoeiro sob o uso de biofertilizante e adubação mineral. Engenharia Agrícola, Jaboticabal, v.31, n.1, p.167-177, 2011.

GERVÁSIO, E. S.; CARVALHO, J. A.; SANTANA, M. J. Efeito da salinidade da água de irrigação na produção da alface americana. Revista Brasileira de Engenharia Agrícola e Ambiental, Campina Grande, v.4, n.1, p.125-128, 2000. https://doi.org/10.1590/S1415-

$\underline{43662000000100023}$

GRACIANO, E. S. A.; NOGUEIRA, R. J. M. C.; LIMA, D. R. M.; PACHECO, C. M.; SANTOS, R. C. Crescimento e capacidade fotossintética da cultivar de amendoim BR 1 sob condições de salinidade. Revista Brasileira de Engenharia Agrícola e Ambiental, v.15, n.8, p.794-800, 2011. https://doi.org/10.1590/S1415-

$\underline{43662011000800005}$

IPA. Recomendações de adubação para o Estado de Pernambuco: 2a aproximação. Recife: IPA, 2008.

LIMA, T. M. Cultivo de amendoim submetido a diferentes níveis de adubação e condições edafoclimáticas no Sudoeste de Goiás. 2011. Dissertação (Mestrado) - Universidade Federal de Goiás, Jataí, 2011.
LUZ, L. N.; SANTOS, R. C.; SILVA FILHO, J. L.; MELHO FILHO, P. A. Estimativas de parâmetros genéticos em linhagens de amendoim baseadas em descritores associados ao ginóforo. Revista Ciência Agronômica, v. 41, n. 1, p. 132-138, 2010.

MACHADO, R. S.; RIBEIRO, R. V.; MARCHIORI, P. E. R.; MACHADO, D. F. S. P.; MACHADO, E. C.; LANDELL, M. G. de A. Respostas biométricas e fisiológicas ao déficit hídrico em cana-de-açúcar em diferentes fases fenológicas. Pesquisa Agropecuária Brasileira, v. 44, p. 1575-1582, $2009 . \quad$ https://doi.org/10.1590/S0100$204 \times 2009001200003$

NETO, J. F.; COSTA, C. H. M.; CASTRO, G. S. A. Ecofisiologia do amendoim. Scientia Agraria Paranaensis, v. 11, n. 4, p. 1-13, 2012. https://doi.org/10.18188/1983-

1471/sap.v11n4p1-13

OLIVEIRA, A. D.; FERNANDES, E. J.; RODRIGUES, T. J. D. Condutância estomática como indicador de estresse hídrico em Feijão. Revista Engenharia Agrícola, v.25, p.86-95, 2005. https://doi.org/10.1590/S0100$\underline{69162005000100010}$

OLIVEIRA, M. R.; SANTOS, R. F.; ROSA, H. A. et al. Manejo da irrigação da cultura do amendoim Arachis hypogaea com base na evaporação. Revista Brasileira de Energias Renováveis, v. 1, p. 33-41, 2012.

SANTOS, R. C.; FREIRE, R. M. M; LIMA, L. M; ZAGONEL, G. F; COSTA, B. J. Produtividade de grãos e óleo de genótipos de amendoim para o mercado olequímico. Revista Ciência Agronômica, Fortaleza, v. 43, n. 1, p. 72-77, 2012. https://doi.org/10.1590/S180666902012000100009

SCARPIN, L. J.; MUNDO NETO, M.; MALAGOLLI, G. A.; O sistema de rotação entre amendoim e canade-açúcar em áreas controladas por industrias. Revista interface Tecnológica, Taquaritinga, v. 1, n. 1, p. 95-103, 2013.

SILVA, F. A. S.; AZEVEDO, C. A. V. The Assistat Software Version 7.7 and its use in the analysis of experimental data. African Journal of Agricultural Research, v. 11, n. 39, p. 3733-3740, 2016. https://doi.org/10.5897/AJAR2016.11522 
SOUSA, P. S.; PORTO FILHO, F. Q.; MEDEIROS, J. F.; MESQUITA, T. O.; OLIVEIRA, C. J. S.; ALMEIDA NETO, A. J.; DIAS, A. F. S. Eficiência do uso da agua pela mamoneira sob diferentes laminas de irrigação. In: CONGRESSO BRASILEIRO DE MAMONA, ENERGIA E RICINOQUÍMICA. Anais [...]. Salvador, 2008. P. 1-5.

TAIZ, L.; ZEIGER, E.; MOLLER, I. M.; MURPHY, A. Fisiologia e desenvolvimento vegetal. Porto Alegre: Artmed, 2017. 